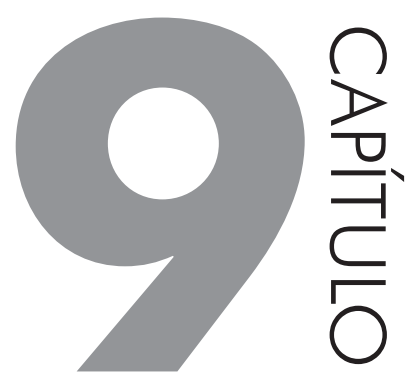

\title{
DESAFIOS PARA MONITORAR A QUALIDADE DA ÁGUA DE LASTRO NO COMPLEXO PORTUÁRIO DO ITAQUI - ESTUDO DE CASO
}

\section{JALILA ANDRÉA SAMPAIO BITTENCOURT}

\subsection{INTRODUÇÃO}

O transporte marítimo internacional de mercadorias movimenta anualmente mais de $80 \%$ das mercadorias do planeta (CARMO, 2006) e, por consequência, movimenta também cerca de 10 bilhões de toneladas de água de lastro, que são descartadas após serem utilizadas como lastro pelos navios transferindo-se assim, a cada dia, aproximadamente, sete mil espécies marinhas invasoras ou exóticas que são introduzidas em ambientes aquáticos que lhes são estranhos (PIMENTEL et al., 2001). Esta invasão já ocasionou, em vários países, diversos danos à biodiversidade e à saúde pública, além de inúmeros prejuízos econômicos.

A troca da água de lastro consiste em uma prática constante entre navios por todo o mundo. Ela visa garantir a segurança do navio, quando este sai do porto de origem sem ou pouca carga, a fim de garantir a estabilidade do mesmo durante a navegação.

Tendo em vista que o transporte marítimo é em grande parte realizado entre países, este tema tem tido uma repercussão crescente e muito se tem discutido acerca das medidas mais adequadas para o gerenciamento e controle da água de lastro, em nível nacional e internacional. 
Neste contexto, este estudo apresentou os resultados do monitoramento e a qualidade da água de lastro no Complexo Portuário do Itaqui, e desta forma identificou as possíveis fragilidades que possam afetar tal monitoramento, bem como, ressaltar a necessidade de os órgãos competentes estabelecerem uma fiscalização eficaz para o gerenciamento da água de lastro no Estado do Maranhão.

\subsection{METODOLOGIA}

A presente pesquisa é um estudo de caso realizado no Complexo Portuário do Itaqui no período de novembro de 2015 a março de 2016. Trata-se de uma pesquisa aplicada, transversal, qualitativa, quantitativa, descritiva, exploratória, aliado a procedimentos bibliográficos e levantamento de dados.

Este estudo foi desenvolvido com base em buscas na internet; leitura de artigos científicos envolvendo o assunto água de lastro, direito ambiental, gestão ambiental; aplicação de questionário com gestores da ANVISA, Capitania dos Portos, Empresa Maranhense de Administração Portuária - EMAP e agentes marítimos. Foi realizada uma consulta por meio de questionário aos capitães dos navios; analise dos registros de deslastre dos navios com auxílio do Google Earth; além de notícias publicadas sobre o tema.

\subsection{CARACTERIZAÇÃO DA ÁGUA DE LASTRO}

\subsubsection{Definição}

Desde os primórdios o homem vem utilizando a água como meio de transporte de mercadorias e pessoas. Inicialmente, as embarcações foram construídas de forma mais artesanal e eram de menor porte. Após sucessivos avanços e desenvolvimento da engenharia naval, foram empregados novos materiais como o aço por exemplo. Vale lembrar, que a expansão marítima proporcionou um maior desenvolvimento do comércio, levando a construção de navios de maior porte para o transporte de mercadorias.

Um grande obstáculo para operação do navio surge neste contexto, pois ele é projetado para transportar além de seu peso, uma estipulada quantidade de carga. Ao viajar completamente carregado, o navio estará em condições estáveis, pois as forças externas que incidem sobre ele (ventos e ondas) não afetam sua segurança. Porém, ao navegar sem carga, poderá ficar instável, ou seja, “com a ação das ondas e do vento sobre a embarcação, poderá acontecer, dependendo da intensidade da força desses elementos, que ele não consiga retornar a sua condição de equilíbrio, com o risco de virar ou afundar" (ÁGUA DE LASTO BRASIL, 2009, p. 10). 
Com o objetivo de reduzir o problema exposto, o navio que realizar a viajem sem ou pouca carga, a fim de não comprometer sua segurança, deverá, portanto, "adicionar um peso extra, com o intuito de garantir que tenha um comportamento estável, conservando seu casco imerso na água”. A este peso adicional, dá-se o nome de lastro (ÁGUA DE LASTO BRASIL, 2009, p. 10).

Anteriormente usava-se o lastro sólido, como pedras, areia e outros materiais pesados e baratos. No entanto, a partir dos anos 80 , trocou-se o lastro sólido pelo líquido, utilizando para tanto, a água por ser mais fácil de carregar e descarregar, sendo mais eficiente e econômica.

Deste modo, pode-se dizer que "o lastro é o carregamento de água do mar ou rios nos tanques dos navios que estão com seus porões vazios, com o objetivo de lhe assegurar condições mínimas de estabilidade, governo e manobra (ÁGUA DE LASTO BRASIL, 2009, p. 11)”.

De acordo com alguns dispositivos, define-se água de lastro como sendo:

(...) água colocada em tanques de uma embarcação com o objetivo de alterar o seu calado, mudar suas condições de flutuação, regular a sua estabilidade e melhorar sua manobrabilidade (art. $1^{\circ}$, IV do anexo Resolução RDC 217/2001, ANVISA - Agência Nacional de Vigilância Sanitária).

(...) a água com suas partículas levada a bordo de um navio nos seus tanques de lastro, para o controle do trim, banda, calado, estabilidade ou tensões do navio (NORMAM 20 - Norma da Autoridade Marítima para o Gerenciamento de Água de Lastro de Navios).

Observa-se que a água de lastro é um elemento fundamental para assegurar a flutuabilidade, navegabilidade e segurança das embarcações.

\subsection{2 Água de lastro no contexto internacional}

A Organização Marítima Internacional - IMO atuante desde 1959 é uma Agência especializada das Nações Unidas, possui, entre outras responsabilidades, a prevenção da poluição marinha por navios. Desde 1988 gerencia o tema sobre água de lastro, através do seu Comitê de proteção ao Meio Ambiente Marinho (MEPC).

Para isso editou a Resolução A.868 (20), de 1997, que sugere as Diretrizes para o Controle e Gerenciamento de Água de Lastro dos Navios para minimizar a transferência de organismos aquáticos nocivos e patogênicos. Em 2004 edita-se a Convenção Internacional para o Controle e Gerenciamento da Água de Lastro dos navios (BMWC) (Pereira, 2013). 
Corroborando a determinação da IMO quanto adotar ações positivas sobre água de lastro, foi criado o Global Ballast Water Management Program, o GLOBALLAST, Revista BW NEWS, cujo propósito maior é auxiliar os governos, autoridades relacionadas com o assunto, comandantes de navios, operadores, armadores, autoridades portuárias e outras entidades afins, para amenizar os riscos de introdução desses organismos aquáticos nocivos e agentes patogênicos, provenientes da água utilizada como lastro pelos navios e sedimentos nela contidos; resguarda, contudo, a segurança dos navios e sua tripulação (IMO, 2017).

A BWMC preconiza que todo navio que utiliza água como lastro deve ser dotado de um Plano de Gerenciamento de Água de Lastro destinado a amenizar a transferência desses organismos nocivos. Esse plano deve fornecer ao Comandante do navio e sua tripulação procedimentos seguros e eficazes para gerenciamento dessa água a bordo e deve fazer parte da documentação operacional do navio. Para isso, deverá conter orientação quanto a métodos de troca e tratamento de água de lastro no navio; deve ter também um Oficial responsável pelo gerenciamento e registros da água de lastro embarcada / desembarcada de bordo (NORMAM 20, 2014).

\subsection{3 Água de lastro no contexto nacional}

A legislação brasileira que trata do meio ambiente, entre outras são: Lei n. 6.938/1981 - Política Nacional de Meio Ambiente; Lei n. 12.815/2013 - Portos e instalações portuárias (Nova Lei dos Portos); Lei n. 9.537/1997 - Lei de Segurança do Tráfego Aquaviário; Lei n. 9.605/1998 - Lei dos Crimes Ambientais e Lei n. 9.966/2000 - Lei de Poluição das Águas.

De acordo com a Lei de Segurança do Tráfego Aquaviário, cabe à DPC (Diretoria de Portos e Costas), como representante da Autoridade Marítima Brasileira (AM), que é o Comandante da Marinha, assegurar, entre outras competências, no mar aberto e hidrovias interiores, a prevenção da poluição ambiental por parte das embarcações, plataformas e suas instalações de apoio.

Assim sendo, a DPC editou a NORMAN-20 (Gerenciamento de Água de Lastro - Organismos Aquáticos, Exóticos nocivos e Agentes Patogênicos), Norma da AM que normatiza as atividades sobre o gerenciamento de Água de Lastro em todos os navios nacionais e estrangeiros, dotados de porões / tanques de água de lastro que utilizam nossos portos e terminais portuários e trafeguem em Águas Jurisdicionais Brasileiras (AJB).

Estabelece a NORMAM-20 (2014) que esses navios devem:

a. Estar sujeitos à Inspeção Naval, a fim de verificar sua conformidade com nossas Normas. 
b. Encaminhar, impreterivelmente, com antecedência mínima de $2 \mathrm{~h}$ após o início da operação do navio, o Formulário sobre Água de Lastro para as autoridades competentes, a fim de ser analisado quanto ao remanejamento dessa água e posteriormente ser encaminhado para o Instituto de Estudos do Mar "Almirante Paulo Moreira", da Marinha do Brasil.

c. Realizar troca de água de lastro de seus tanques/ porões pelo menos a 200 milhas náuticas da terra mais próxima e numa profundidade mínima de 200m; caso haja impossibilidade operacional de cumprir essa determinação, que realize a troca a pelo menos 50 milhas náuticas e em águas de profundidade de pelo menos $200 \mathrm{~m}$; essa troca deve atingir, no máximo, 95\% do volume da água de lastro existente a bordo; com isso, somente os tanques/ porões que efetuam a troca poderão ser deslastrados a área portuária.

d. Os sedimentos de água de lastro só poderão ser descarregados no mar nas mesmas condições estabelecidas para troca da água de lastro.

e. Se procedente do exterior e tiver necessidade de deslastrar em AJB deve ter trocado a totalidade da água de lastro em águas oceânicas, antes da chegada ao primeiro porto/ terminal portuário nacional.

f. Apresentar, o Plano de Gerenciamento de Água de Lastro, aprovado por uma Sociedade Classificadora, assim como o Livro de Registro de Água de Lastro e Certificado Internacional de Gestão de Água de Lastro.

g. Propiciar, a fim da verificação das informações lançadas no Formulário, aos Inspetores Navais, amostras da água de lastro dos tanques, para serem analisadas pelo refratômetro quanto à sua salinidade e densidade.

\subsubsection{Efeitos resultantes da transferência da água de lastro}

Quando a água de lastro é despejada em local diferente do qual foi coletada, milhares de espécies marinhas são lançadas a um novo ecossistema. Calcula-se que o transporte marítimo de cargas, "transfere internacionalmente de 3 a 5 bilhões de toneladas de água de lastro a cada ano, sendo que consequentemente proporciona o transporte diário de pelo menos 7.000 espécies entre diferentes regiões do globo". (KESSELRING, 2007).

Algumas destas espécies são consideradas nocivas ou patogênicas porque, se implantadas em regiões diferentes do seu habitat natural, englobando águas marinhas e estuários, ou em cursos de água doce, podem causar impactos ambientais, prejudicando a biodiversidade biológica, criando riscos à saúde humana, trazendo enfermidades ou mesmo a morte, podem ainda causar impactos econômicos, como a deterioração de instalações, tubulações e cascos das embarcações, redução da atividade pesqueira, enfim, como podemos perceber, os prejuízos são relativamente grandes, daí a preocupação com o tema (Pereira, 2013). 
Uma das características dos organismos aquáticos nocivos e patogênicos é que constantemente se tornam "invasores", ou seja, por não possuírem predadores naturais, acabam se adaptando e se multiplicando rapidamente, ocupando o habitat natural das espécies nativas (Pereira e Brinati, 2012; Pereira et al., 2014).

Segundo Kesselring (2007), as principais espécies identificadas no Brasil e no Mundo são:

No mundo:

- Mexilhão Zebra Europeu (Dreissena polymorpha) - infestou nos Estados Unidos, 40\% das vias navegáveis do país entre os anos de 1989 e 2000.

- Alga marinha asiática (Undaria pinnatifida) - está invadindo novas áreas da Austrália e desalojando comunidades nativas.

- Água viva filtradora norte americana (Mnemiopsis leidyi) - atingiu o Mar Negro causando um colapso na pesca comercial da região.

No Brasil:

- Vibrião colérico (Vibrio cholerae) - tido como suspeito por causar um surto de cólera no Paranaguá.

- Siri bidu (Charybdis hellerii) - espécie marinha de crustáceo de origem indo-pacífica, que no Brasil prejudicou a pesca do siri nativo da Bahia. Foi observado nas Baias de Guanabara e Sepetiba e no Estado de São Paulo.

- Isognomon bicolor - espécie de molusco bivalve de origem indo-pacífica, que habita as regiões entremarés da Bahia à Santa Catarina.

- Algumas espécies de algas tóxicas - nativas de outras localidades, foram observadas em várias regiões do Brasil. Causam irritações na pele humana e matam algumas espécies de animais marinhos, acabando por tornar mariscos impróprios para o consumo.

- Mexilhão dourado (Limnoperna fortunei) - molusco bivalve originário dos rios asiáticos é o principal responsável pela maior bioinvasão no território brasileiro.

\subsection{RESULTADOS}

Este estudo de caso foi realizado no Complexo Portuário do Itaqui, no qual trafegam anualmente cerca de 1600 navios, considerando todos os navios que circulam no seu entorno. A maioria dos navios que circulam nestas águas são graneleiros que carregam minério de ferro ou soja, ou descarregar bauxita, fertilizantes e carvão. 
Para a pesquisa foram realizadas sucessivas visitas ao porto e aos navios que atracaram somente no porto do Itaqui (Figura 53), onde foram aplicados questionários com perguntas abertas a respeito do tema tanto para os comandantes dos navios, quanto para os gestores dos órgãos envolvidos, tais como, EMAP, ANVISA, agências marítimas, Vale e Capitania dos Portos. Além dos questionários, foram analisados os registros de água de lastro dos navios no período de novembro de 2015 a março de 2016.

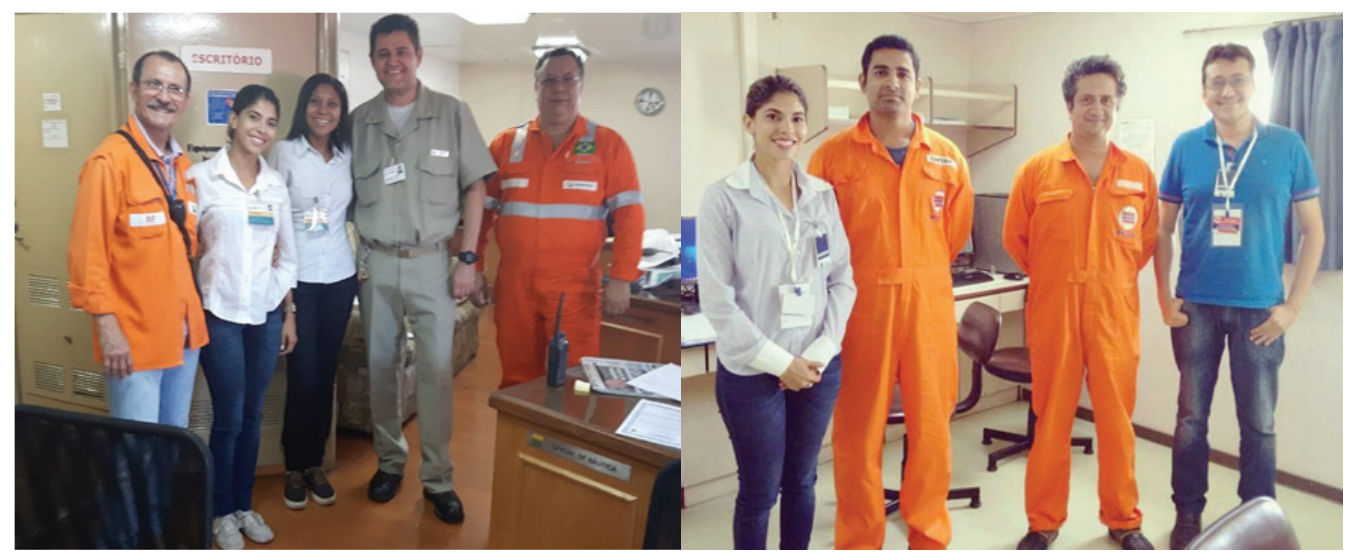

Figura 53 Visita aos navios para condução de entrevistas

Fonte: Próprio autor

No total foram aplicados cerca de sete questionários com comandantes das embarcações, cinco questionários com gestores, e foram analisados cerca de 26 registros de água de lastro. Ao aplicar os questionários, percebemos certa resistência por parte de alguns comandantes e gestores. Alguns comandantes se negavam a ler, outros delegavam aos seus imediatos a função de responder os questionários. Um gestor se negou a responder e só o fez após uma declaração expedida pela Universidade Federal do Maranhão e protocolada no respectivo órgão, outro questionou sobre o tema pesquisado em relação ao curso que autora estava realizando.

Ademais, ao analisar os questionários respondidos pelos gestores, percebeu-se que a grande maioria, apresenta um conhecimento básico acerca do tema água de lastro.

Vale ressaltar, que diversas vezes não foi possível acesso a área primária e desta forma perdemos a oportunidade de visitar um número considerável de navios. Isto acontecia em virtude restrição no controle de acesso à área primária.

Ao questionar os órgãos envolvidos na gestão da água de lastro a respeito do seu monitoramento, percebeu-se que ele ainda é feito de forma deficiente no Estado. 
Apenas a Autoridade Marítima, na competência da Capitania dos Portos do Maranhão (CPMA) é quem realiza em parte este monitoramento, com análises físicas da água de lastro e seus respectivos registros, que também são encaminhados ao Instituto de Estudos do Mar "Almirante Paulo Moreira". Os demais órgãos apenas recebem os registros de água de lastro. Ao questionar também sobre a quantidade de navios que já foram autuados por não cumprimento da NORMAM-20, todos responderam não ter ocorrido nenhuma falha por descumprimento da norma.

Nenhum órgão do Estado realiza análise microbiológica dos navios contendo água como lastro, bem como, a grande maioria dos portos nacionais. Ao questionar a ANVISA e CPMA sobre a problemática, ambas afirmaram não possuir recursos, e que as Universidades locais embora já tenham realizado tais pesquisas, atualmente não vem manifestando interesse em solicitar parcerias para realização das pesquisas. A ANVISA possui um quadro de funcionários reduzido, possuem um total de sete funcionários, com apenas três trabalhando nos turnos, portanto, pode-se afirmar que a quantidade de pessoas para fiscalizar e coletar amostras é insuficiente devido ao grande contingente de navios que aportam neste complexo.

Em virtude disto e do grande potencial na transferência de micro-organismos patogênicos presentes na água do lastro, é que inicialmente optou-se por realizar além dos procedimentos citados anteriormente, análises físicas, químicas e microbiológicas, englobando um total de oito análises (temperatura, salinidade, $\mathrm{pH}$, condutividade elétrica, total de sólidos dissolvidos, total de oxigênio dissolvido, coliformes totais e contagem de Escherichia coli).

No entanto, as análises acabaram não sendo concluídas em razão de inúmeras dificuldades que ocorreram no decorrer desta pesquisa. A primeira dificuldade encontrada ocorreu na própria Universidade Federal do Maranhão, na busca de laboratórios e escassez de profissionais habilitados para auxiliar nas análises. A resistência de alguns comandantes em liberar as amostras foi outra dificuldade obtida. Outro empecilho foi no acesso aos reagentes e materiais, elevando o custo da pesquisa, alguns chegaram a ser obtidos, porém doados.

Outro fator, foi a pesquisa bibliográfica, devido à escassez de fontes envolvendo o assunto no Maranhão, por se tratar de um Estado com grande potencial de comércio marítimo e extensa faixa litorânea; por fim, o obstáculo que realmente impactou de forma significativa para não realização das análises, foi o pouco tempo obtido para tal, que se tornou reduzido em consequência das greves, feriados prolongados, recessos e férias docentes na Universidade Federal do Maranhão. 
A CPMA, como Agente da Autoridade Marítima no Maranhão, possui um Grupo de Vistorias e Inspeções, GVI, que monitora o cumprimento da Legislação e procedimentos sobre a água de lastro nos navios que atracam em nossos portos e terminais portuários. Para isso, possui duas equipes de Inspetores, totalizando oito Inspetores qualificados e certificados internacionalmente pela DPC, que realizam entre outras atividades, inspeções em navios nacionais e estrangeiros que aqui trafegam. Um dos itens de inspeção é a verificação in loco, do cumprimento das Normas em vigor sobre a água de lastro. Para isso, vem adotando os seguintes procedimentos:

a. Analisar os Relatórios de Água de Lastro recebido dos navios $24 \mathrm{~h}$ antes de chegar à área portuária, a fim de verificar a quantidade de água de lastro existente a bordo e se foi efetivada a troca oceânica; após essa análise é decidido se o navio pode ou não operar em nosso Complexo Portuário;

b. Quando da Inspeção Naval a bordo dos navios, verifica a existência do Ballast Water Management Plan, aprovado pela Sociedade Classificadora. Caso o navio possua o Plano, mas que não esteja aprovado pela Sociedade Classificadora, está passível de ser penalizado com multas e recomendado de somente voltar às AJB com o Plano de Gerenciamento de Água de Lastro devidamente aprovado. Caso o navio não possua Plano a bordo, será determinado que seja interrompida a sua operação de carga/ descarga, desatracando e retirando-se das AJB;

c. Realiza a medição da salinidade e densidade da água de lastro existente a bordo, a fim de verificar se aquela água é de origem oceânica. Caso a água não seja oceânica, o navio deve parar sua carga/ descarga e buscar águas oceânicas para trocar sua água de lastro. Será penalizado com multas e adotadas providencias administrativas severas;

d. Realiza orientação ao Comandante e Imediato sobre a necessidade da troca oceânica efetiva da água de lastro recebida em áreas portuárias.

As inspeções são realizadas por amostragem em consequência do pequeno número de Inspetores existentes (oito). Prioritariamente as inspeções acontecem no Terminal de Ponta da Madeira, nos navios graneleiros tipo Valemax, por apresentar uma quantia considerável de água de lastro (aproximadamente $150 \mathrm{mil}$ toneladas). Portanto, é essencial uma vistoria minuciosa nestes navios em razão da grande quantidade de água que é deslastrada.

As inspeções são feitas nestas embarcações, pois como mencionado, os mesmos chegam sem carga, ou seja, em lastro. No porto do Itaqui, muitos navios chegam sem realizar a troca da água de lastro, todavia, com a instalação do Terminal de Grãos do Maranhão - TEGRAM houve um crescente aumento no número de navios que atracam contendo água de lastro. 
Diante do exposto, percebe-se que com a verificação in loco da salinidade e densidade por meio do refratômetro, é possível verificar se foi realizada a troca oceânica da água de lastro ou não. O padrão de referência é de $\geq 35 \%$ para salinidade $\mathrm{e} \geq 1,25 \mathrm{~g} / \mathrm{ml}$ para densidade. A água oceânica apresenta uma maior salinidade e densidade em comparação às águas fluviais e salobras. Por isso, se houver a troca, os resultados obtidos estarão dentro do padrão.

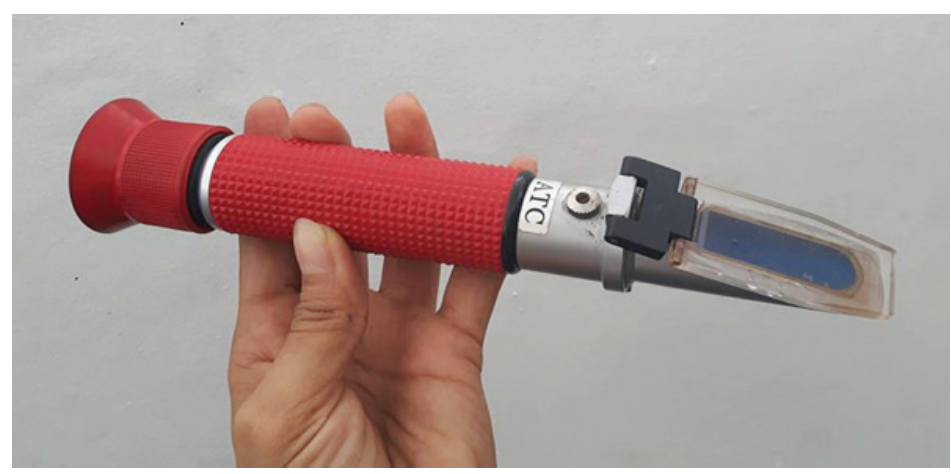

Figura 54 Refratômetro utilizado nas medições de salinidade

Com isso, surge outra problemática, a retirada da obrigatoriedade da segunda troca da água de lastro para a região amazônica. Na resolução anterior da NORMAM-20, eram obrigatórias as duas trocas, a primeira era realizada para a eliminação e minimização de agentes patogênicos, a segunda para diminuir a salinidade presente no lastro. Ao indagar os gestores sobre esta flexibilização da norma, a maioria respondeu não compactuar com tal decisão, e acredita que o aumento da salinidade em vias interiores pode prejudicar a biota local.

O Porto do Itaqui é considerado um Hub Port de combustível e derivados. Ao analisar os registros de água de lastro dos navios gaseiros e petroleiros, observou-se que grande parte deles, não apresentava quaisquer informações sobre trocas oceânicas de água de lastro, por se tratar de um porto concentrador, e os navios desembarcarem cheios de carga.

Com a observação dos relatórios, percebeu-se que os navios de longo curso, apresentam seus relatórios melhor preenchidos de acordo com a Normam em comparação aos de cabotagem. Discutiu-se o porquê desta situação com um Inspetor da CPMA, ele afirmou que na cabotagem entre portos marítimos não é obrigatório realizar a troca, mas sim entre portos marítimos e fluviais.

No entanto, a temperatura, salinidade, bem como, alguns animais marinhos, difere-se de uma região para outra, com isso, torna-se essencial à realização da troca da água de lastro mesmo entre portos nacionais. Ao perguntar sobre a existência de áreas sensíveis em nosso Complexo, o Inspetor respondeu não 
possuir, contudo, é sabido, que o nosso litoral apresenta uma vasta área de mangue. Considerando que por ser um berço da biodiversidade nacional, seria importante à demarcação destas áreas no intuito de preservar, o maior número de espécies possíveis.

Ao analisar o material coletado, percebemos que o tempo médio de experiência de cada comandante, bem como o grau de instrução e o período de tempo em que eles estudaram, não condiz com as respostas preenchidas nos questionários, apesar de possuírem conhecimentos suficientes para respostas concretas, muitos deixaram várias questões em branco, não dando importância devida ao tema.

Em relação aos gestores, somente um respondeu todas as questões de forma satisfatória, este possuía maior tempo de experiência portuária, enquanto os demais apresentaram ter um conhecimento básico em relação ao assunto.

Ao analisar as operações envolvendo a água de lastro, e questionar os riscos expostos, $57 \%$ dos capitães entrevistados, relatou que os riscos envolvem problemas com a estabilidade dos navios. Enquanto para os gestores, $100 \%$, ou seja, todos os entrevistados, responderam ser a bioinvasão o maior risco envolvendo a água como lastro.

Dos 26 formulários de água de lastro expedidos pelos navios de acordo com a Normam-20/DPC, a grande maioria é do tipo oil tanker. Portanto, estes navios estavam carregados de combustível para descarregar no porto do Itaqui, com isso, navegam sem lastro. Estes navios possuem uma tonelagem bruta em média de 24 a 35 mil toneladas, tendo, portanto, uma capacidade de carga e de lastro consideráveis.

Ao analisar estes formulários, percebemos que muitos não apresentavam as informações necessárias, com vários campos em branco e não conformidade das unidades de medida. Dos 26 formulários 10 não apresentavam nenhum tipo de coordenada geográfica. 3 não possuíam informação cargas e 3 apresentavam somente coordenadas da origem da água. 10 realizaram a troca conforme a Normam; 3 realizaram a troca a menos de 200 milhas, sendo 2 a mais de $500 \mathrm{~m}$ (dentro da Norma) e 1 não apresentava o campo profundidade preenchido (classificou-se fora da Norma). Logo, pode-se concluir, que dos 26 formulários analisados, 7 não estão em conformidade e 19 estão em conformidade.

Somente os 26 navios analisados, foram responsáveis por despejar $1.071 .203,38 \mathrm{~m}^{3}$ de água de lastro. Se analisarmos o volume de água de lastro despejada durante um ano de todos os navios que atracam no porto, teremos um percentual elevado desta água, sendo que muitas vezes ela não é feita a troca oceânica a 200 milhas náuticas da costa conforme exigência da norma. Sendo justificável a importância do assunto pesquisado. 


\subsection{CONSIDERAÇÕES FINAIS}

Diante de tudo que foi apresentado, pode-se perceber que o desafio no monitoramento da qualidade da água de lastro no Complexo Portuário do Itaqui ainda está distante dos padrões desejáveis, quando comparado com outros portos no mundo.

Entretanto, fazem-se necessárias uma maior preocupação dos comandantes em relação à necessidade da troca da água de lastro. Também é fundamental, adotar a prática do tratamento por meio de sua troca, para uma eficaz redução da bioinvasão de agentes nocivos e patogênicos. Enquanto, as embarcações que operam em águas brasileiras não disponham de sistemas a bordo, deve ser reforçado a necessidade da troca continua da água de lastro como medida preventiva de bioinvação.

No mais, apesar de toda dificuldade envolvendo o monitoramento da água como lastro, a pesquisa despertou o interesse da EMAP, para o tema abordado, propondo uma parceria para realização do monitoramento por meio de análises laboratoriais dos navios atracados no porto do Itaqui. Sendo assim, pode-se concluir que a pesquisa logrou resultados positivos, mostrando também o compromisso da administração portuária com a necessidade de manter um monitoramento da qualidade da água de lastro despejada no porto.

\subsection{REFERÊNCIAS}

A água de lastro e seus riscos ambientais. Cartilha de conhecimentos básicos. São Paulo: Água de Lastro Brasil, p. 10-11, 2009. Disponível em:<ftp://ftp. sp. gov.br/ftppesca/ agua_lastro.pdf>. Acesso em: 10 fev. 2016.

AMAZÔNIA INFORMA. Mexilhão dourado: uma invasão que ameaça p Pantanal e a Amazônia. Nov. 2014. Disponível em: <http://amazoniainforma.blogspot.com. br/2014/11/mexilhao-dourado-uma-invasao-que-ameaca.html?view=magazine $>$. Acesso em: 29 jun. 2016.

BRASIL. Agência Nacional de Vigilância Sanitária. Resolução RDC n.o 217, de 21. nov.2001. Disponível em:<http://www.anvisa.gov.br/paf/legislacao/resol.htm>. Acesso em: 10 fev. 2016.

. DIRETORIA DE PORTOS E COSTAS - DPC. NORMAM 8. Trafego e permanência de embarcação em águas jurisdicionais brasileiras. Disponível em: <https://www. dpc.mar.mil.br/normam/N_08/N_08.htm>. Acesso em: 10 fev. 2016.

. DIRETORIA DE PORTOS E COSTAS - DPC. NORMAM-20/DPC, de 14. jun. 2005. Norma da autoridade marítima para o gerenciamento da água de lastro de navios da diretoria de portos e costas. Disponível em: <https://www.dpc.mar.mil.br/ normam/N_20/Introducao.pdf>. Acesso em: 10 fev. 2016. 
. Lei 24.548, de 03 de julho de 1934. Dispõe sobre Regulamento do Serviço de Defesa Sanitária Animal. Disponível em: <http://www.planalto.gov.br/ccivil_03/_ ato2011-2014/2013/Lei/L12815.htm>. Acesso em: 15 fev. 2016

. Lei 6.938, de 31 de agosto de 1981. Dispõe sobre a Política Nacional do Meio Ambiente, seus fins e mecanismos de formulação e aplicação, e dá outras providências. Disponível em: <http://www.planalto.gov.br/ccivil_03/leis/L6938.htm>. Acesso em: 20 fev. 2016.

. Lei 9.966, de 28 de abril de 2000. Dispõe sobre a prevenção, o controle e a fiscalização da poluição causada por lançamento de óleo e outras substâncias nocivas ou perigosas em águas sob jurisdição nacional e dá outras providências. Disponível em: <http:// www.planalto.gov.br/ccivil_03/leis/L9966.htm>. Acesso em: 4 mar. 2016.

. Lei 9.605, de 12 de fevereiro de 1998. Dispõe sobre as sanções penais e administrativas derivadas de condutas e atividades lesivas ao meio ambiente, e dá outras providências. Disponível em: <http://www.planalto.gov.br/ccivil_03/leis/L9605.htm>. Acesso em: 4 mar. 2016.

. Lei 9.537, de 11 de dezembro de 1997. Dispõe sobre a segurança do tráfego aquaviário em águas sob jurisdição nacional e dá outras providências. Disponível em: <http:// www.planalto.gov.br/ccivil_03/leis/19537.htm>. Acesso em: 4 mar. 2016.

. MARINHA DO BRASIL. Convenção Internacional Sobre Controle e Gestão Da Água de Lastro e Sedimentos de Navios - BWM 2004. Disponível em: <https://www. ccaimo.mar.mil.br/sites/default/files/convencao_bwm.pdf>. Acesso em: 18 dez. 2015.

CARMO, Maria Chauviere. Água de lastro. Ministério da Defesa: Exército Brasileiro. Secretaria de Ciência e Tecnologia. Instituto Militar de Engenharia. Rio de Janeiro: 2006.

CONQUILIOLOGISTAS DO BRASIL. Isognomon bicolor. 2001-2016. Disponível em: <http://www.conchasbrasil.org.br/conquiliologia/descricao.asp?id=881>. Acesso em: 29 jun. 2016.

INTERNATIONAL MARITIME ORGANIZATION - IMO. RESOLUTION A.868(20), of 27 November 1997. Guidelines for the control and management of ships' ballast water to minimize the transfer of harmful aquatic organisms and pathogens. Disponível em: <http://globallast.imo.org/wp-content/uploads/2015/01/Resolution-A.868_20_english.pdf>. Acesso em: 18 dez. 2015.

KESSELRING, Ana Beatriz. A introdução de espécies marinhas exóticas em águas brasileiras pela descarga da água de lastro de navios. Revista de Direito Ambiental. ano 12. vol. 45. São Paulo: RT, 2007. p. 11-34.

MARINE INVASIONS RESEARCH LAB. Undaria pinnatifida. Abr. 2010. Disponível em: <http://www.serc.si.edu/labs/marine_invasions/MIRL_at_RTC/undaria.aspx>. Acesso em: 29 jun. 2016.

PEREIRA, J.P.F.N. 2013. Monitoramento de água de lastro na zona portuária de Santana/AP: suporte às políticas públicas de gerenciamento. Dissertação de Mestrado do PPGDAPP/UNIFAP. $122 \mathrm{p}$. 
PEREIRA, N. N.; BOTTER, R. C.; FOLENA, R. D.; PEREIRA, J.P.F.N.; CUNHA, A. C. (2014). Ballast water: a threat to the Amazon Basin. Marine Pollution Bulletin., 2014 (in press).

PEREIRA N.N, BRINATI HL. Onshore ballast water treatment: A viable option for major ports. Marine Pollution Bulletin. 2012.

OLIVEIRA, OMP; et al. Mnemiopsis leidyi. Disponível em: <http://www.usp. br/cbm/ ctenophora/en/ctenophoraen_files/Page511.htm>. Acesso em: 29 jun. 2016.

PIMENTEL, D. et al. Economic and environmental threats of alien plant, animal, and microbe invasions. Agriculture, Ecosystems and Environment. v. 84, p. 1-20, 2001.

WIKIPÉDIA. Siri Bidu. Nov. 2014. Disponível em: <https://pt.wikipedia.org/wiki/Siri_ bidu>. Acesso em: 29 jun. 2016.

.Cólera.Jun.2016.Disponívelem:<https://pt.wikipedia.org/wiki/C\%C3\%B3lera>. Acesso em: 29 jun. 2016.

. Mexilhão-zebra. Jun. 2015. Disponível em: <https://pt.wikipedia.org/wiki/ Mexilh\%C3\%A3o-zebra>. Acesso em: 29 jun. 2016. 